\title{
COMPARISON OF BRAY CURTIS AND NEI'S GENETIC DISTANCE ON MANTEL TEST FOR CHICKEN DIVERSITY DATA
}

\author{
Hasan ÖNDER ${ }^{1 *}$, Levent MERCAN² \\ ${ }^{1}$ Department of Animal Science, Faculty of Agriculture, Ondokuz Mayıs University, 55139, Samsun, Turkey \\ ${ }^{2}$ Department of Agricultural Biotechnology, Faculty of Agriculture, Ondokuz Mayıs University, 55139, \\ Samsun, Turkey
}

Received: January 31, 2020; Accepted: March 03, 2020; Published: July 01, 2020)

\begin{abstract}
Attempts to machine harvest cotton in Turkey essentially began in 1996. In the period beginning from 1969 until 1996, some brand, for time to time to test the market, imported and demonstrated cotton harvesting machines with spindle and saw type pickup units which harvest losses were more than the acceptable limit. In 1996, with the arrival of spindle machines of American origin that harvest losses were less than the acceptable limit, machine harvesting show continuity. This shows that cotton harvesting machine picking technology has been an important factor in harvest continuity and increase. Technological developments and innovations on spindle system machines which are still used today are increasing day by day. In this study, cotton harvesting machines that from past to present used in Turkey market introduced. Researches have done on harvest efficiency of its technologies and aimed to create resource on this topic. As a result of the research, it has been determined that every improvement made at the technological level is a reason for preference and completed some deficiencies experienced during and after harvest, and many technologies on machinery have not yet been applied in our country's harvest conditions due to qualified deficiencies.
\end{abstract}

Keywords: Mantel test, Bray Curtis distance, Nei's genetic distance, Chicken

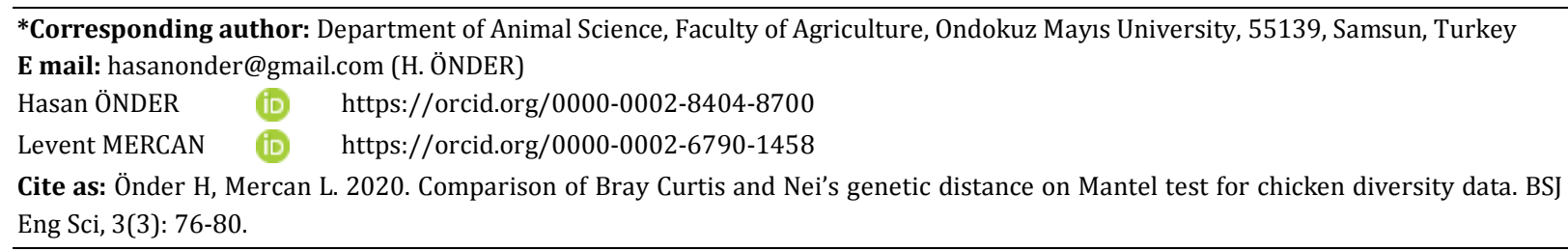

\section{Introduction}

Mantel test (Mantel 1967; Mantel and Valand 1970) allows linear or monotonic comparisons between the elements of two distance matrices. The Mantel statistic is usually tested by permutation although it can be tested using an asymptotic normal approximation when the number of observations, n, is large. Since Mantel and Valand (1970), the procedure, known as the Mantel test in the biological and environmental sciences, includes any analysis relating two distance matrices or, more generally, two resemblance or proximity matrices. In population genetics, Mantel tests have been used to determine whether local populations that are 
geographically close are either genetically or phylogenetically similar (Legendre or Fortin, 2010). That is Mantel test used to explore significance and scale of relationship between spatial genetic variation and geographic distances. Many researchers (Sharma et al., 2013; Sahoo et al., 2013; Costa et al., 2013) used Nei's (1972) genetic distance which measure that genetic differences arise due to mutations and genetic drift. However, some researchers used (Bennett and Gratton, 2013; Maurice et al., 2013; Blum et al., 2012) Bray Curtis distance which used to quantify the compositional dissimilarity between two different sites, based on counts at each site.

The objective of this study was to examine the effects of both Nei's genetic distance and Bray Curtis distance versus geographical distance for Mantel test on chicken data.

\section{Material and Method}

The experimental procedures of this study were approved by the Local Animal Care and Ethics Committee of Ondokuz Mayis University, Samsun, Turkey (approval number: 2008/47).

Turkish local chickens' blood samples were collected from 5 provinces including 3 counties with 3 villages or districts located in the Central Black Sea Region of Turkey. The map driven with GPS (Global Positioning System) coordinates of the sampling locations of the village populations was shown in Figure 1 (Mercan and Okumuş, 2015). In all villages at least 3 and at most 5 flocks were randomly selected. At least one male and one female village chickens were collected in each population.

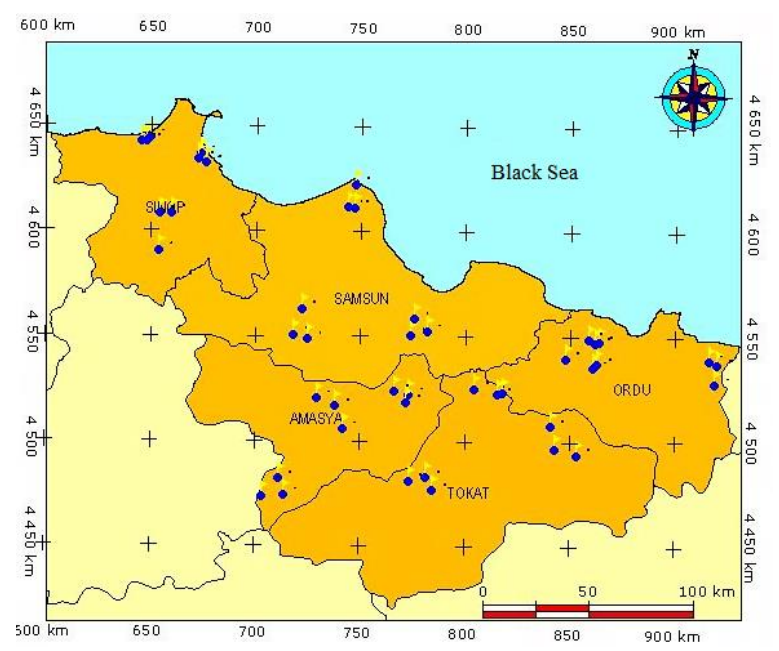

Figure 1. Study Sampling locations of village chicken populations (Mercan and Okumus, 2015).

Twenty-eight autosomal microsatellite DNA markers based genetic distance data of the populations was calculated from row data received from Mercan (2010). Geographical distance between locations were measured as the Euclidean distance (in $\mathrm{km}$ ) using the ruler implemented in Google Earth version 4 and natural logarithm of geographic distances were used (Procházka et al, 2011).

To explore the relationship between genetic and geographic distances among populations, simple Mantel test can be used. The statistic used for the measure of the correlation between the matrices is the classical Pearson correlation coefficient;

$$
r=\frac{1}{N-1} \sum_{i=1}^{N} \sum_{j=1}^{N}\left[\frac{\left(A_{i j}-\bar{A}\right)}{s_{A}}\right]\left[\frac{\left(B_{i j}-\bar{B}\right)}{s_{B}}\right]
$$

Where $N$ is the number of elements in the lower or upper triangular part of the matrix, $\bar{A}$ is mean for $A$ elements and $S_{A}$ is the standard deviation of $A$ elements. This coefficient measures the linear correlation and hence is subject to the same statistical assumptions. Consequently, if nonlinear relationships between matrices exist, they will be degraded or lost.

If matrices $A$ and $B$ normalized:

$a_{i j}=\frac{A_{i j}-\bar{A}}{S_{A}} ; b_{i j}=\frac{B_{i j}-\bar{B}}{S_{B}}$,

than it goes to:

$\bar{a}=0 ; S_{a}=1 ; \bar{b}=0 ; S_{b}=1$

which simplifies equation (1) as:

$r=\frac{1}{N-1} \sum_{i=1}^{N} \sum_{j=1}^{N} a_{i j} b_{i j}$

This coefficient measures the linear correlation and hence is subject to the same statistical assumptions. Consequently, they will be degraded or lost, if non-linear relationships between matrices exist.

The testing procedure for the simple Mantel test goes as follows:

Assume two symmetric dissimilarity matrices $A$ and $B$ of size $n \times n$. The rows and columns correspond to the same objects. The first step is to compute the Pearson correlation coefficient between the corresponding elements of the lower (or upper)-triangular part of the matrices.

1) Compute the reference value $r_{A B}$ using equation.

2) Permute randomly rows and the corresponding columns of one of the matrices, creating a new matrix $A$

3) Compute the $r_{A^{\prime} B}$ statistic between matrix $A^{\prime}$ and matrix $B$ using equation.

4) Repeat steps 2 and 3 a great number of times $(>5000)$. This will constitute the reference 
distribution under the null hypothesis. The number of repeats determine the overall precision of the test ( » 1000 for $\mathrm{a}=0.05$; » 5000 for $\mathrm{a}=0.01$; » 10000 for greater precision (Manly 1997).

5) For a one-tailed test involving the upper tail of the distribution, the $p$ value is equal to the proportion of values $r_{\hat{A}}{ }^{\prime} B C$ greater than or equal to $r_{A B . C .}$ Symmetrically, the $p$ value for the lower tail is the proportion of values $r_{A}^{\prime} B . C$ smaller than or equal to $r_{A B . C}$ (Bonnet and Van de Peer, 2002).

In this study both Nei's genetic distance and Bray Curtis distance were used to compare their effects.

Nei's genetic distance could be calculated as (Hillis, 1984);

$D=-\ln I$

where $I=\Sigma x_{i} y_{i} /\left(\Sigma x_{i}^{2} \Sigma y_{i}^{2}\right)^{0.5}$

and Bray Curtis distance could be calculated as;

$d_{j k}=\frac{\sum_{i}\left|x_{j i}-x_{k i}\right|}{\sum_{i} x_{j i}+x_{k i}}$

which shows for the distance between samples $j$ and $k$ (Koren et al, 2013).

After building the genetic and geographical distance matrices, genetic differentiation and geographical distance was compared with Mantel test (Mantel 1967; Procházka et al, 2011) using the software zt (Bonnet and Van de Peer, 2002). Significance was tested using permutation methods (10 000 randomizations) to obtain exact type I error rate (Legendre and Fortin, 2010).

\section{Results and Discussion}

364 backyard chickens were successfully genotyped at the 28 microsatellite loci. All loci were polymorphic, showing 6 to 28 alleles and relatively high expected heterozygosity ranging between 0.544 and 0.770 .

There was a significant positive correlation between the level of genetic differentiation and the natural logarithm of geographic distance among all pairs of backyard chicken populations for Nei's genetic distance ( $r=0.518589 ; \mathrm{p}=0.000010)$ and for Bray Curtis distance $(r=0.530520 ; p=0.000010)$. Relationship between genetic differentiations and geographic distance (loge) between populations for all samples were given in Figure 2 and Figure 3. Some descriptive statistics for Bray Curtis distance and Nei's genetic distance belongs to data were given in Table 1.
Table 1. Descriptive statistics for Bray Curtis distance and Nei's genetic distance

\begin{tabular}{lcc}
\hline & Bray Curtis distance & Nei's genetic distance \\
\hline Min & 0.526 & 0.158 \\
Max & 1.00 & 0.96 \\
Mean & 0.859 & 0.769 \\
Std dev & 0.084 & 0.103 \\
CV (\%) & 9.732 & 13.347 \\
\hline
\end{tabular}

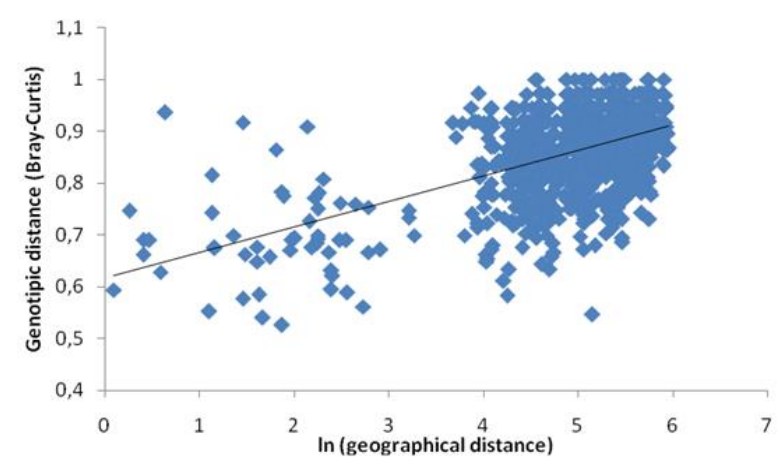

Figure 2. Relationship between genetic differentiation (Bray Curtis distance) and geographic distance (loge) between populations for all samples.

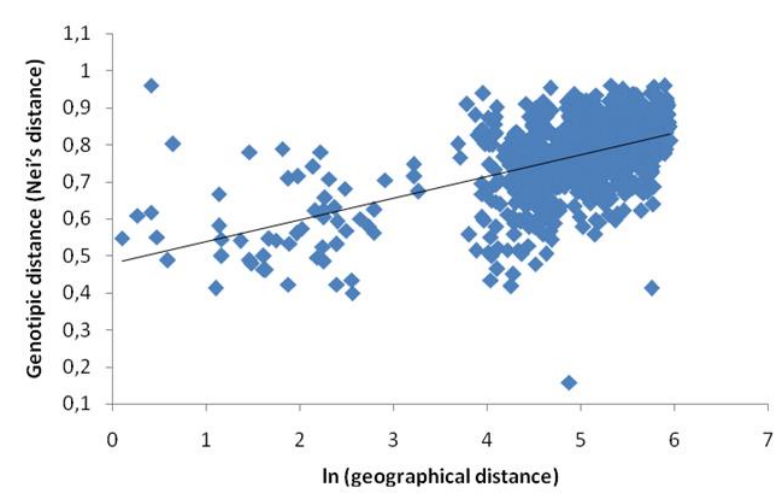

Figure 3. Relationship between genetic differentiation (Nei's genetic distance) and geographic distance (loge) between populations for all samples

When the Table 1 examined, it was easily understood that coefficient of variation (CV) value of Bray Curtis distance was smaller than value of Nei's genetic distance. This value showed that Bray Curtis distance measure narrowed the range of data which could be seen with comparison of Figure 2 and Figure 3. Nei's genetic distance produced values with higher deviance than Bray Curtis distance.

Koren et al. (2013) declared that Bray Curtis distance measure had a moderate effect to limit the data for clustering. Mason et al. (2012) showed that Bray Curtis distance produced more reliable distance measures than other distance measures for comparison. For the genetic diversity studies Papadoupoulou et al. (2011) used bray 
Curtis distance measure for species-genetic diversity correlation and declared that this distance measure could be applied accomplishedly. Beler et al. (2012) showed that Bray Curtis distance was more reliable than Euclidean distance for genotypic data. Cordier et al. (2012) showed that Bray Curtis distance could be used in Mantel test to calculate relationship between genetic and geographic distance. Shiro et al. (2013) introduced that Bray-Curtis measure reliably described the structure and geographical distribution of the genotypic data than others. İkinci and Oberprieler (2010) used Bray Curtis distance measure to calculate genetic relationships for Lilium L. species and declared that Bray Curtis distance measure was more reliable than Nei's genetic distance, which was support the results of the study conducted by Odat et al. (2004). Møller et al. (2013) denoted that Bray Curtis distance was more efficient for genotypic analysis. All that studies supported our results that Bray Curtis distance was superior to Nei's genetic distance to calculate relationship between genetic differentiations and geographic distance between populations.

This situation could be caused form the distance values in Bray-Curtis measure never exceed one, so this measure performed exceptionally well than all other distance metrics (Kokare, et al., 2003). Also the Bray-Curtis distance measure is semimetric and so, that measure could be used in ecological, biological and genomic applications (Anderson, 2006).

Bray Curtis distance measure is also suitable to calculate linear combinations of variables (Parker et al., 2012). Also this distance measure can be easily adapted to data (Peres-Neto et al., 2006). Bray Curtis measure was also superior to other distance metrics on intrapopulation genetic diversity studies (Eckholm et al., 2011).

\section{Conclusion}

In Mantel test to calculate relationship between genetic differentiations and geographic distance between populations Bray Curtis distance could be used substituted for Nei's genetic distance with great reliability on chicken diversity data. For further studies, the other distance measures can be compared on genotypic data in matrix comparison or other statistical techniques such as clustering and discrimination.

\section{Conflict of interest}

The authors declare that there is no conflict of interest.

\section{Research and Publication Ethics}

In this research article, "Higher Education Scientific Research and Publication Ethics Guidelines rules" of the Black Sea Journal of Agriculture was followed.

\section{Acknowledgements}

A part of this study has been published as an abstract in the abstract book of 66th Annual Meeting of the European Federation of Animal Science, Warsaw, Poland, 31

\section{August-4 September 2015.}

\section{References}

Anderson MJ. 2006. Distance-Based tests for homogeneity of multivariate dispersions. Biometrics, 62: 245-253.

Beier S, Mohit V, Ettema TJG, Östman Ö, Tranvik LJ, Bertilsson S. 2012. Pronounced seasonal dynamics of freshwater chitinase genes and chitin processing. Environ Microbiol, 14(9): $2467-$ 2479.

Bennett AB, Gratton C. 2013. Floral diversity increases beneficial arthropod richness and decreases variability in arthropod community composition. Ecol Applicat, 23: 86-95.

Blum MJ, Bagley MJ, Walters DM, Jackson SA, Daniel FB, Chaloud DJ, Cade BS. 2012. Genetic diversity and species diversity of stream fishes covary across a land-use gradient. Oecologia, 168: 83-95.

Bonnet, E, Van de Peer Y. 2002. ZT: a software tool for simple and partial Mantel tests. J Stat Software, 7: 1-12.

Cordier T, Robin C, Capdevielle X, Desprez-Loustau ML, Vacher C. 2012. Spatial variability of phyllosphere fungal assemblages: genetic distance predominates over geographic distance in a European beech stand (Fagus sylvatica). Fungal Ecol, 5: 509-520.

Costa D, Bouchon D, Van Straalen NM, Sousa JP, Riberio R. 2013. Copper tolerance and genetic diversity of porcellionides sexfasciatus (ISOPODA) in a highly contaminated mine habitat. Environmental Toxicol Chem, 32(4): 884-888.

Eckholm BJ, Anderson KE, Weiss M, DeGrandi-Hoffman G. 2011. Intracolonial genetic diversity in honeybee (Apis mellifera) colonies increases pollen foraging efficiency. Behav Ecol Sociobiol, 65: 1037-1044.

Hillis DM. 1984. Misuse and Modification of Nei's genetic distance. System Zool, 33(2): 238-240.

İkinci N, Oberprieler C. 2010. Genetic relationships among NE Turkish Lilium L. (Liliaceae) species based on a random amplified polymorphic DNA analysis. Plant Syst Evol, 284: 4148.

Kokare M, Chatterji BN, Biswas PK. 2003. Comparison of similarity metrics for texture image retrieval, TENCON 2003. Conference on Convergent Technologies for the Asia-Pacific Region, 2: 571-575, 15-17 October 2003, Bangalore, India.

Koren O, Knights D, Gonzalez A, Waldron L, Segata N, Knight R, Huttenhower C, Ley RR. 2013. A guide to enterotypes across the human body: meta-analysis of microbial community structures in human microbiome datasets. PLOS Computat Biol, 9(1): 1-16.

Legendre P, Fortin MJ. 2010. Comparison of the Mantel test and alternative approaches for detecting complex multivariate relationships in the spatial analysis of genetic data. Molec Ecol Resour, 10: 831-844.

Mantel N. 1967. The detection of disease clustering and a generalized regression approach. Cancer Res, 27: 209-220.

Mason KL, Erb Downward JR, Mason KD, Falkowski NR, Eaton KA, Kao JY, Young VB, Huffnagle GB. 2012. Candida albicans and bacterial microbiota interactions in the cecum during recolonization following broad-spectrum antibiotic therapy. Infect Immun, 80(10): 3371-3380.

Maurice CF, Haiser HJ, Turnbaugh PJ. 2013. Xenobiotics shape the physiology and gene expression of the active human gut microbiome. Cell, 152(1-2): 39-50.

Mercan L. 2010. Analysis of genetic dissimilarity between native and commercial chicken genotypes by SSR (Simple sequence repeats) method. PhD Thesis, Ondokuz Mayis University Natural Science Institute, p. 155, Samsun. 


\section{Black Sea Journal of Engineering and Science}

Mercan L, Okumuş A. 2015. Genetic diversity of village chickens in Central Black Sea Region and commercial chickens in Turkey by using microsatellite markers. Turkish J Vet Anim Sci, 39: 134-140.

Møller AK, Søborg DA, Al-Soud WA, Sørensen SJ, Kroer N. 2013. Bacterial community structure in High-Arctic snow and freshwater as revealed by pyrosequencing of $16 \mathrm{~S}$ rRNA genes and cultivation. Polar Res, 32: 1-11.

Nei M. 1972. Genetic distance between populations. The American Natural, 106(949): 283-292.

Odat N, Jetschke G, Hellwig FH. 2004. Genetic diversity of Ranunculus acris L. (Ranunculaceae) populations in relation to species diversity and habitat type in grassland communities. Molec Ecol, 13: 1251-1257.

Papadopoulou A, Anastasiou I, Spagopoulou F, Stalimerou M, Terzopoulou S, Legakis A, Vogler AP. 2011. Testing the species-genetic diversity correlation in the Aegean archipelago: Toward a haplotype-based macroecology? The American Natural, 178(2): 241-255.

Parker KA, Anderson MJ, Jenkins PF, Brunton DH. 2012. The effects of translocation-induced isolation and fragmentation on the cultural evolution of bird song. Ecol Letters, 15: 778-
785.

Peres-Neto PR, Legendre P, Dray S, Borcard D. 2006. Variation partitioning of species data matrices: estimation and comparison of fractions. Ecol, 87(10): 2614-2625.

Procházka P, Stokke BG, Jensen H, Fáinova D, Bellinvia E, Fossøy F, Vikan JR, Bryja J, Soler M. 2011. Low genetic differentiation among reed warbler Acrocephalus scirpaceus populations across Europe. J Avian Biol, 42: 103-113.

Sahoo PK, Mohanty J, Garnayak SK, Mohanty BR, Kar B, Jena J, Prasanth H. 2013. Genetic diversity and species identification of Argulus parasites collected from major aquaculture regions of India using RAPD-PCR. Aquaculture Res, 44: 220-230.

Sharma A, Dutt G, Jayakumar S, Saroha V, Verma NK, Dixit SP. 2013. Genetic structuring of nine indian domestic goat breeds based on SNPs identified in IGF-1 gene. Anim Biotech, 24(2) 148-157.

Shiro S, Matsuura S, Saiki R, Sigua GC, Yamamoto A, Umehara Y, Hayashi M, Saeki Y. 2013. Genetic diversity and geographical distribution of indigenous soybean-nodulating bradyrhizobia in the United States. Appl Environ Microbiol, 79(12): 36103618 . 